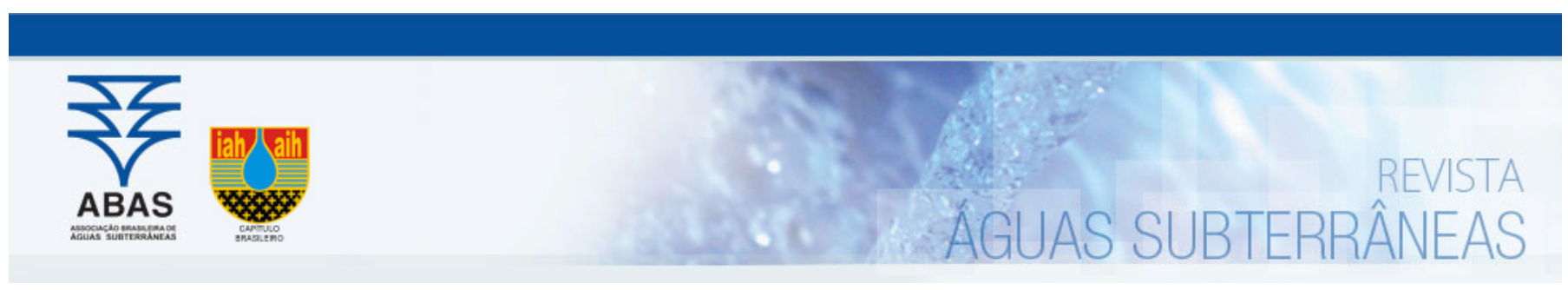

Estudos de Caso e Notas Técnicas

\title{
Qualidade da Água da Bacia do Rio Pindaré, nos trechos correspondentes aos Municípios de Pindaré- Mirim, Tufilândia e Alto Alegre no Estado do Maranhão
}

\section{Quality of the water from the Pindare river Basin, In the facts corresponding to the municipalities of Pindare Mirim, Tufilandia and Alto Alegre In the State of Maranhao}

\begin{abstract}
Maria Raimunda Chagas Silva1 ; Leonilde Vatanabe da Silva2 ; Larissa Nascimento Barreto² ; Eduardo Henrique Costa Rodrigues 3 ; Rita de Cássia Mendonça de Miranda1 ; Denilson Silva Bezerra2; Dagolberto Calazans Araujo Pereira1 ${ }^{\bowtie}$
\end{abstract}

1 Universidade CEUMA, São Luís, MA, Brasil.

2 Universidade Federal do Maranhão (UFMA), São Luís, MA, Brasil.

3 Universidade Estadual Paulista "Júlio de Mesquita Filho", São Paulo, SP, Brasil.

$\square$ marirah@gmail.com; leonildevatanabe@yahoo.com.br; laraufma@yahoo.com.br; ehc.1988@hotmail.com; ritamend30@gmail.com; denilson_ca@yahoo.com.br; dagolberto@gmail.com

\begin{tabular}{|c|c|}
\hline & Resumo \\
\hline $\begin{array}{l}\text { Palavras-chave: } \\
\text { Sustentabilidade. } \\
\text { Rio. } \\
\text { Características limnológicas. } \\
\text { Qualidade ambiental. }\end{array}$ & $\begin{array}{l}\text { O presente estudo objetivou caracterizar físico-quimicamente a água da região do médio curso do Rio Pindaré sob jurisdição } \\
\text { dos municípios de Pindaré- Mirim, Tufilândia, e Alto Alegre/MA. A fim de obter uma amostra representativa, foi coletada água } \\
\text { em dez pontos distintos distribuídos no Rio Pindaré, ao longo de } 24 \text { meses em diferentes períodos sazonais, nos anos de } 2010 \\
\text { e } 2011 \text {. Os parâmetros físico-químicos analisados foram: temperatura, pH, turbidez, condutividade elétrica, oxigênio dissolvido } \\
\text { e os íons amônio (NH4+), nitrito (NO2-), nitrato (NO3-) e fósforo total (PO43-). Durante o período de estudo, foi observada ampla } \\
\text { variação na maioria das variáveis analisadas, com destaque para o fósforo total (PO43-) e a condutividade elétrica que apre- } \\
\text { sentou resultados superiores aos estabelecidos pela resolução CONAMA 357/05. Quanto ao pH, as águas do Rio Pindaré foram } \\
\text { na maior parte do tempo ácidas. As concentrações médias de nitrato variaram de } 0,249 \text { mgL-1 (período seco) e } 0,267 \text { mgL-1 } \\
\text { (período chuvoso). Dos pontos coletados nos diferentes períodos, apenas no município de Alto Alegre se observou diferença } \\
\text { estatística significativa quando o parâmetro testado foi o pH. Quando os parâmetros testados foram a condutividade elétrica e } \\
\text { os ions amônio, nitrito e nitrato, observou-se diferença estatística significativa em todos os pontos testados nos três municípios } \\
\text { com ps } 0,05 \text {. Os resultados mostraram que o Rio Pindaré possui uma boa qualidade ambiental, apesar de apresentar desmata- } \\
\text { mento em suas margens comprometendo assim a sustentabilidade da bacia. As características físicas e químicas foram de } \\
\text { extrema importância na dinâmica do ecossistema aquático sendo que os valores encontrados são considerados adequados } \\
\text { para manutenção da vida aquática, segundo a resolução do CONAMA } 357 / 2005 \text {. }\end{array}$ \\
\hline & Abstract \\
\hline
\end{tabular}

Keywords:

Sustainability.

River.

Limnological characteristics.

Environmental quality.

\section{Revisado por pares.}

Recebido em: 30/08/2017.

Aprovado em: 09/09/2017.

This study aimed to characterize chemical-physical water area of the middle reaches of the river Pindare under the jurisdiction of the municipalities of Pindaré- Mirim, Tufilândia and Alto Alegre / MA. In order to obtain a representative sample, water was collected in ten different points distributed in Rio Pindaré over 24 months in different seasonal periods in 2010 and 2011 . The physical-chemical parameters analyzed were: temperature, $\mathrm{pH}$, turbidity, electrical conductivity, dissolved oxygen and ammonium ion (NH4 +), nitrite (NO2), nitrate (NO3) and total phosphorus (PO43-). During the study period, there was wide variation in most of the variables analyzed, with emphasis on the total phosphorus (PO43-) and electrical conductivity presented results higher than those established by Resolution CONAMA 357/05. As to pH, the water of the river Pindare were mostly acidic time. The average nitrate concentrations ranged from $0.249 \mathrm{mg} \mathrm{L-1}$ (dry season) and $0.267 \mathrm{mg} \mathrm{L-1}$ (rainy season). The points collected in different periods, in the municipality of Alto Alegre was no significant statistical difference when the tested parameter is $\mathrm{pH}$. When the parameters tested were the electrical conductivity and ion ammonium, nitrite and nitrate, a statistically significant difference was observed in all points tested in three municipalities with $p=0.05$. The results showed that the river Pindaré has a good environmental quality, despite its deforestation along its banks thereby undermining the sustainability of the basin. The physical and chemical characteristics were extremely important in the dynamics of the aquatic ecosystem and the values found are considered suitable for maintenance of aquatic life, according to Resolution CONAMA 357/2005.

DOI: http://dx.doi.org/10.14295/ras.v31i4.28929

\section{INTRODUÇÃO}

O planejamento ambiental, sobre o qual as ações de uso adequado dos recursos naturais precisam ser expressas sobre uma dimensão geográfica, apresenta a bacia hidrográfica como a grande unidade para a concepção do planejamento e a exe- 
cução de projetos na área de meio ambiente (ATLAS DO MARANHÃO, 2002).

O Estado do Maranhão possui um grande potencial hídrico, formado principalmente por bacias hidrográficas, bacias lacustres e águas subterrâneas, ocupando uma área territorial de $325.650 \mathrm{~km}^{2}$ (MARANHÃO, 2006). O Estado possui nove bacias hidrográficas (Atlas do Maranhão, op. cit.), caracterizadas por sua grande extensão e volume de água. Dentre elas encontrase a Bacia do Rio Pindaré, que é a terceira em termos de área e um dos maiores potenciais hídricos a ser utilizado para o abastecimento da capital do Estado.

A análise de qualidade da água pode ser baseada na comparação de características físico-químicas com padrões estabelecidos para os diversos tipos de usos previstos, tais como consumo humano e irrigação. Ao analisar esses parâmetros poder-se apontar as operações que envolvem o uso e o manejo do solo, levando a concluir quais as que mais exercem influência na qualidade da água (SANTANA et. al. 2011).

Os efeitos das atividades humanas na qualidade da água são normalmente complexos e específicos para cada região, dependendo de uma série de fatores físico-bioquímicos. O conhecimento das variáveis físicas, químicas e biológicas das águas de um rio, lago ou reservatório é de fundamental importância para a caracterização do sistema hídrico, já que existem diversas formas de utilização desse sistema, tais como o abastecimento público, a irrigação, o lazer, a manutenção da vida aquática, entre outros (PEREIRA et al. 2007). Com isso surgiram maiores exigências com relação à conservação e ao uso racional dos recursos hídricos (BRAGA et al., 2003).

Como resultado do crescimento populacional, aumento da atividade agropecuária e uso não sustentável dos seus recursos naturais, a Bacia do Rio Pindaré/MA vem sofrendo diversos tipos de impactos ambientais que incluem desmatamento, erosão, lançamento de rejeitos contendo esgotos domésticos, fertilizantes e pesticidas que, em conjunto, têm afetado negativamente os recursos hídricos locais (SEMATUR, 1991 apud SILVA, 2015).

Deve-se ressaltar, que o uso não sustentável dos recursos naturais na bacia de drenagem, particularmente dos solos, transforma zonas agrícolas e urbanas em áreas produtoras de sedimentos e poluentes, os quais são transferidos ao longo dos anos para os corpos d'água, resultando em prejuízos do ponto de vista social, econômico e ecológico. Os sedimentos revelam a integração de todos os processos biológicos, físicos e químicos que ocorrem em um ecossistema aquático (PANE \& BRONDI, 2008).

Nesse aspecto, a integração de dados químicos da água foi utilizada como forma de avaliar a qualidade ambiental da Bacia do Rio Pindaré, especificamente para os municípios de Pindaré- Mi- rim, Tufilândia e Alto Alegre, gerando informações úteis ao delineamento de propostas de conservação e gerenciamento para a região, na busca de alternativas para os problemas evidenciados e para um melhor aproveitamento das potencialidades locais.

\section{MATERIAL E MÉTODOS}

\section{1 Área de Estudo}

A Bacia do Rio Pindaré está localizada na porção Noroeste do Estado do Maranhão, ocupando uma área de 40.400 km², correspondendo $12 \%$ do Estado (SEMATUR, 1991). O Rio Pindaré, principal afluente do Rio Mearim, nasce nas elevações que formam o divisor de águas entre as bacias hidrográficas dos rios Mearim e Tocantins, nas proximidades da cidade de Amarante, em cotas da ordem de $300 \mathrm{~m}$, tem como principais afluentes os Rios Buriticupu, Negro, Paragominas, Zutiua, Timbira, Água Preta e Santa Rita. Seu percurso total é de aproximadamente $686 \mathrm{~km}$ (BACIAS DO NORDESTE, 2000). Dentre os diversos rios maranhenses, destaca-se como o mais piscoso e de importância para a navegação, contribuindo no abastecimento de água das cidades ribeirinhas (LEITE, 1976).

A principal atividade econômica da região é a agropecuária. 0 solo é caracterizado como Latossolo Amarelo e Podzólico Vermelho Amarelo. A cobertura vegetal é classificada como Floresta Ombrófila Densa (ATLAS DO MARANHÃO, 2002). A vegetação ciliar marginal apresenta baixos índices de conservação, predominantemente nas cidades que se desenvolveram as margens do rio sendo a ocupação antrópica a principal causa da erosão das margens e assoreamento do rio.

O município de Pindaré - Mirim possui área de $245 \mathrm{~km}^{2}$ e sua população é de 31.145 habitantes. Teve o seu topônimo alterado para Pindaré-Mirim, pelo decreto-lei Estadual $n^{\circ} 820$, de 30 de dezembro de 1943, desmembrado de Vitória do Mearim. Localiza-se na mesorregião oeste maranhense e possui coordenada de $03^{\circ} 36^{\prime} 30^{\prime \prime}$ latitude e $45^{\circ} 20^{\prime} 36^{\prime \prime}$ longitude (IBGE, 2010). O município de Tufilândia localiza-se na parte Oeste do Estado do Maranhão e participa da Amazônia Legal, sendo formado somente pelo distrito-sede que possui coordenadas 45 $33^{\prime} 14$ ' 40" de longitude oeste e $3^{\circ} 43^{\prime} 44,40$ " latitude sul. Foi criado pela lei 6180 de 10/01/1997, sendo sua área proveniente do município de Pindaré-Mirim (IBGE, 2010). 0 município de Alto Alegre do Pindaré limita-se ao Norte com o município de Bom Jardim; a Leste com os municípios de Pindaré-Mirim e Santa Luzia; a Oeste com os municípios de Buriticupu e Bom Jardim e ao Sul com o município de Santa Luzia (IBGE, 2010). 
Figura 1- Localização da Bacia do Rio Pindaré, nos trechos dos municípios de Pindaré-mirim, Tufilândia e Alto Alegre/MA

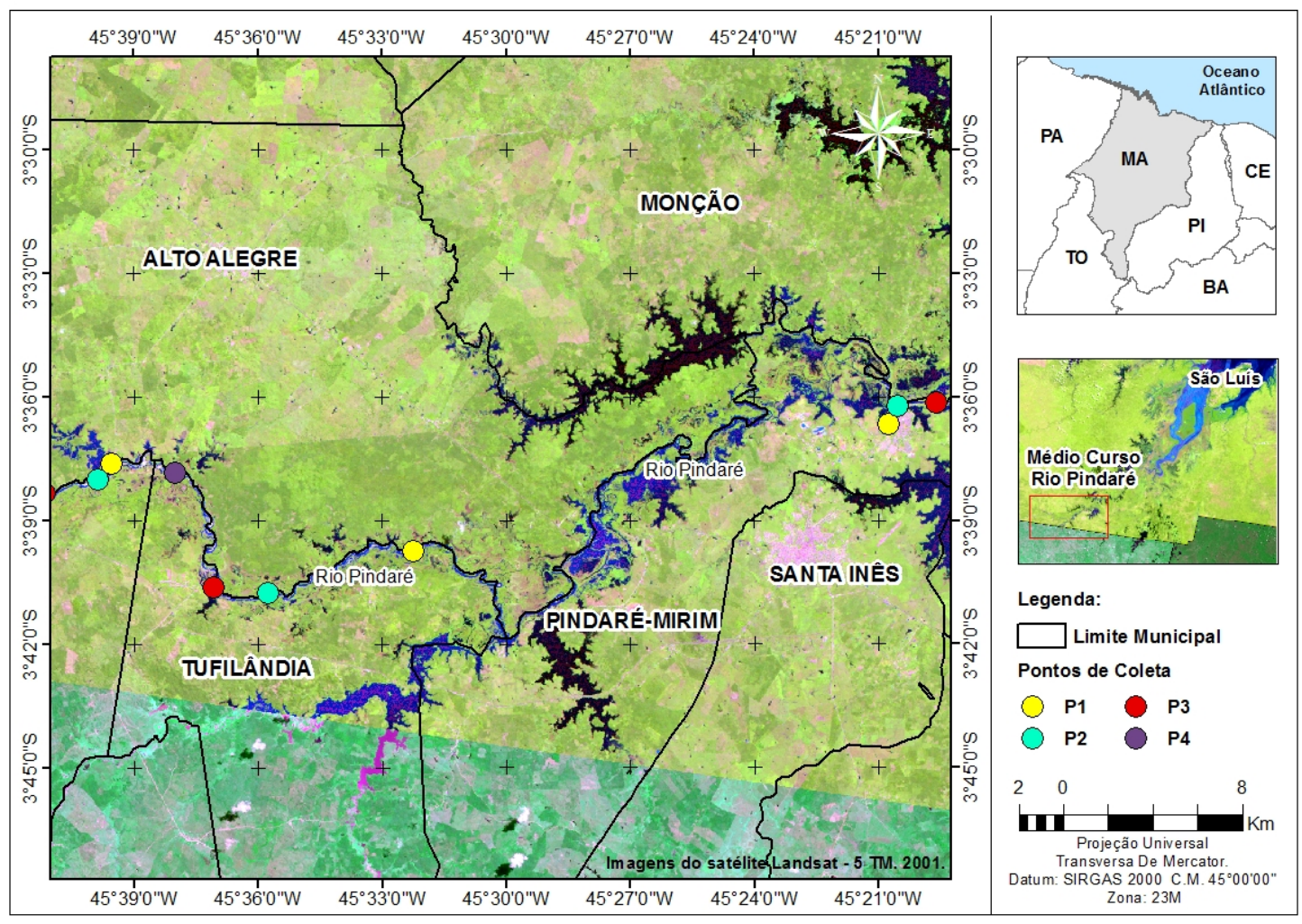

\subsection{Variáveis Físicas e Químicas da Água}

As amostragens de água foram realizadas em um período de 24 meses em períodos sazonais distintos: período seco (agosto e novembro/ 2010 e 2011) e chuvoso (maio / 2010 e maio 2011), em dez pontos distribuídos ao longo do Rio Pindaré, sob jurisdição dos municípios de Pindaré- Mirim, Tufilândia, e Alto Alegre.

As amostras de água para determinação dos parâmetros temperatura, oxigênio dissolvido, condutividade, turbidez, potencial hidrogêniônico $(\mathrm{pH})$, fósforo total, amônia, nitrito e nitrato foram coletadas a $20 \mathrm{~cm}$ da superfície com auxílio da garrafa de Van Dorn com capacidade para 5 litros. Após a coleta, as amostras destinadas à determinação do oxigênio dissolvido foram transferidas para frascos de vidro, preservadas com soluções de sulfato de manganês e alcali-iodeto e mantidas à temperatura ambiente, enquanto que aquelas reservadas para análise dos íons foram acondicionadas em frascos de polietileno e mantidas em caixa isotérmica com gelo $\left( \pm 4^{\circ} \mathrm{C}\right)$.

As variáveis físicas como temperatura, $\mathrm{pH}$, turbidez e condutividade elétrica foram obtidas in situ através de um multiparâmetro digital Horiba U-10.

Para análise dos nutrientes as amostras foram filtradas em membranas de microfibra de vidro WHATMAN GF/C (47 mm de diâmetro) e analisadas seguindo os procedimentos recomendados pelos autores a seguir: amônio - F. Koroleff, descrito em Aminot (1983); fósforo total - Nanzel e Valand (1964) e Nanzel e Corvin (1965); nitrito e nitrato de acordo Golterman et al., (1978). Todas as leituras dos nutrientes foram realizadas a partir de réplicas, utilizando cubetas de $1 \mathrm{~cm}$ em espectrofotômetro Shimadzu UV 1601 PC.
A análise do oxigênio foi realizada seguindo o método baseado na técnica descrita por Winkler (1888) e modificado por Strickland \& Parsons (1968) apud Goltermanet al. op. cit.

A fim de verificar se havia diferença estatística significativa em relação a sazonalidade nos diferentes municípios estudados, foi realizada uma análise utilizando a metodologia do teste $t$-Student considerando $p \leq 0,05$.

As variáveis limnológicas (oxigênio dissolvido, $\mathrm{pH}$, temperatura, condutividade elétrica, turbidez e concentrações de amônio, nitrito, nitrato e fósforo total) foram incluídos em uma análise estatística de Cluster e na Análise dos Componentes Principais (ACP) a fim de verificar a associação entre estas variáveis com os corpos d'água amostrados, assim como as influências dos distintos períodos hidrológicos (JOHNSON; WICHERN, 1998; HONGYU, 2015).

\section{RESULTADOS E DISCUSSÃO}

\subsection{Variáveis Físicas e Químicas da Água}

Analisando os dados observa-se que em Pindaré-Mirim os pontos amostrados se apresentaram com variação significativa, como mostra a Figura $2.0 \mathrm{pH}$ foi predominantemente ácido em todas os pontos, com os valores variando entre um mínimo de 6,4 (P1-nov/10) e máximo de 6,7 (P1-ago/11 e P2-nov/10) no período seco, e no chuvoso foi mínimo de 6,1 (P2- mai/10) e máximo de 6,5 (mai/11) em todos os pontos. Em Tufilândia foram obtidos valores entre 6,4 (P2- nov/10, P1 e P2- ago/11) e 6,9 (P1- nov/10), e entre 5,5 (P2- mai/10) e 6,8 (P3- mai /11) nos períodos seco e chuvoso, respectivamente. Já em Alto Ale- 
gre, os valores variaram entre 5,8 (mai/10) em todos os pontos, no período chuvoso, e para o período seco, os mesmos se apresentaram alcalinos com 7,9 (P2 e P3- nov/10).

A temperatura do Rio em Pindaré-Mirim apresentou-se com valor mínimo de $26^{\circ} \mathrm{C}$ (mai/10) no período chuvoso e máximo de $32,7^{\circ} \mathrm{C}(\mathrm{P} 1$-ago/11) no seco. Em Alto Alegre a mesma se apresentou com mínimo de $25^{\circ} \mathrm{C}$ (mai/10) no período chuvoso e no seco se apresentou constante em todos os pontos com máximo de $29^{\circ} \mathrm{C}$. Já em Tufilândia a temperatura apresentou valor máximo de $30^{\circ} \mathrm{C}$ (P4-ago/11) no período seco e mínimo de $23^{\circ} \mathrm{C}$ (maio/10) no chuvoso.

Em relação à condutividade elétrica, o município de Pindaré registrou valor mínimo de $170 \mu \mathrm{S} . \mathrm{cm}^{-1}$ (P3- ago/11) e máximo de $326 \mu$ S.cm-1 (P3- ago/11) no período seco e mínimo de 167 $\mu \mathrm{S} . \mathrm{cm}^{-1}$ (P3 mai /11) e máximo de $184 \mu \mathrm{S} . \mathrm{cm}^{-1}$ (P2- mai/10) no chuvoso. Em Alto Alegre, se obteve um mínimo de $200 \mu \mathrm{S} . \mathrm{cm}^{-1}$ (P3- ago/11) e máximo de $357 \mu \mathrm{S} . \mathrm{cm}^{-1}$ (P1- nov/10) no período seco, já para o chuvoso o mínimo foi de $155 \mu \mathrm{S} . \mathrm{cm}^{-1}$ (P3mai/10) e máximo de $237 \mu$ S.cm-1 (P2 mai /11). Em Tufilândia os valores apresentaram no período seco um mínimo de 205 $\mu \mathrm{S} . \mathrm{cm}^{-1}$ (P2- ago/11) e máximo de $359 \mu{\mathrm{S} . \mathrm{cm}^{-1}}^{-1}$ (P- nov/10) e no chuvoso obteve mínimo de $180 \mu \mathrm{S} . \mathrm{cm}^{-1}$ (P4-mai/10) e máximo de $230 \mu \mathrm{S} . \mathrm{cm}^{-1}$.

Os valores de turbidez para o município de Pindaré - Mirim apresentaram valores entre 19,8 UNT (P3-ago/11) e 29,2 UNT (P1- ago/11) para o período seco e entre 18,3 UNT (P3-mai/10) e 29,6 (P1-mai/11) para o chuvoso. Em Alto Alegre o mínimo obtido foi de 20,2 (P3- ago/11) e máximo de 30,2 UNT (P1-ago/11) no período seco e mínimo de 19,6 UNT (P3-mai/10) e máximo de 32,1 (P1-mai/10) no chuvoso. Para Tufilândia os valores variaram entre 15,2 (P3-ago/11) a 30,0 UNT (P1ago/11) no período seco, já no chuvoso a variação foi entre 17,3 UNT (P3-jun/11) e 31,3 UNT (P1- mai/10). Em novembro este parâmetro não pôde ser detectado por problemas técnicos.

Os valores de oxigênio dissolvido observados em Pindaré-Mirim apresentaram valor mínimo de 5,52 mg L-1 (P2- mai /11) no período chuvoso e máximo de 7,3 (P2-nov/10) no seco. Em Alto Alegre as concentrações ficaram entre $6,28 \mathrm{mg} \mathrm{L}^{-1}$ (P3-nov/10) e 8,24 mg L-1 (P1-nov/10) no período seco, já para o chuvoso as concentrações ficaram entre $7,20 \mathrm{mg} \mathrm{L}^{-1}$ (P2- mai /11) e $7,71 \mathrm{mg} \mathrm{L}^{-1}$ (P1 mai/11). No município de Tufilândia para o período seco as concentrações foram entre $5,3 \mathrm{mg} \mathrm{L}^{-1}$ (P4- nov/10) e 7,4 mg L-1 (P2-nov/10) e para o período chuvoso foram entre $5,7 \mathrm{mg} \mathrm{L}^{-1}$ (P4- mai /11) e 7,54 mg L-1 (P3- mai/10).

Quanto às concentrações das formas de nitrogênio, o amônio apresentou valores variando entre $0,035 \mathrm{mgL}^{-1}$ (P3-ago/11) e $0,15 \mathrm{mgL}^{-1}$ (P2-ago/11) no período seco e entre $0,18 \mathrm{mgL}^{-1}$ (P3mai/10) e 0,03 mgL-1 (P3- mai /11) no período chuvoso para o município de Pindaré-Mirim. Já em Alto Alegre a variação foi de 0,04 mgL-1 (P2-ago/11) e de 0,57 mgL-1 (P3-nov/10) no período seco e entre 0,03 mgL-1 (P2 mai /11) e 0,18 mgL-1 (P3-mai/10) no chuvoso. Para Tufilândia os valores se apresentaram variando entre 0,05 mgL-1 (P3 e P4-ago/11) e 0,62 mgL-1 (P1nov/10) no período seco, já no período chuvoso foi registrado uma variação entre $0,06 \mathrm{mgL}^{-1}$ (P4- mai /11) e 0,19 $\mathrm{mgL}^{-1}$ (P3mai/10).
Foram observadas as variações nas concentrações de fósforototal para Pindaré-Mirim no qual apresentou no período seco uma variação entre $0,36 \mathrm{mgL}^{-1}$ (P1-nov/10) e 0,69 $\mathrm{mgL}^{-1}(\mathrm{P} 2-$ nov/1), e no período chuvoso ficou entre $0,42 \mathrm{mgL}^{-1}$ (P1- mai /11) e $0,85 \mathrm{mgL}^{-1}$ (P1-mai/10). Para Alto Alegre as concentrações apresentaram valores entre $0,42 \mathrm{mgL}^{-1} \mathrm{em}$ novembro para todos os pontos amostrados e $0,55 \mathrm{mgL}^{-1}$ (P1-ago/11) no período seco, e para o período chuvoso a variação foi de 0,48 (P3mai/11) e 0,72 (P1-mai/10). Em Tufilândia os valores ficaram entre $0,4 \mathrm{mgL}^{-1}$ (P3- nov/10) e 0,69 mgL-1 (P1-nov/10) no período seco, e no chuvoso, foi registrado uma variação entre 0,38 $\mathrm{mgL}^{-1}$ (P3-mai/10) e 0,88 $\mathrm{mgL}^{-1}$ (P1-mai/10).

Observando os valores conclui-se que em todos os municípios o $\mathrm{pH}$ da água encontra-se em um meio ácido, exceto para Tufilândia que se apresentou básico em todos os pontos de amostragens no mês de maio de 2010. Os baixos valores de pH encontrados em Tufilândia podem ser explicados devido a influência de plantio de arroz na beira do rio que causa um forte assoreamento desprotegendo a área da margem. Os valores de $\mathrm{pH}$ estão de acordo com a resolução do CONAMA 357/05 que tem como faixa entre 6 e 9 para rios de classe 2. Padrões semelhantes foram obtidos por Schneider et. al. (2011), em estudo sobre a qualidade da Bacia hidrográfica do Rio Pirapó/Paraná, onde encontrou valores entre 6,7 e 8,5. Betemps et al. (2014), avaliou o impacto ambiental de manejo agrícola na qualidade da água do riacho Arroio do Padre (RS) através da análise físicoquímica da água e constatou um baixo impacto ambiental causado pelo manejo agrícola no riacho. Assim como neste trabaIho, os autores relataram que todos os parâmetros avaliados estavam dentro do determinado pela legislação CONAMA 357/05 para águas doce de classe I.

A temperatura mostrou que os pontos amostrados foram influenciados de acordo com os períodos do ano, a variação foi considerada estável, evidenciando uma baixa amplitude térmica, fato que pode ser devido ao processo de mistura das águas dos rios. Variações sazonais semelhantes foram observadas por Guimarães (2011) em trabalho realizado no Rio Gurguéia ao sul do Estado do Piauí e por Monteiro (2008) no Rio preguiças.

Andrade et al. (2016), avaliando as características físico-quimicas do lago Macurany em Parintins - AM, não observou diferenças nas características nos períodos secos e chuvosos em relação a pH e temperatura. Os autores relataram que embora não tenham encontrado diferença desses parâmetros os diferentes períodos, houve variação sazonal na concentração microbiana.

Os dados sobre a condutividade elétrica, mostrou que os valores elevados podem estar relacionados com o aporte de material particulado na coluna d'água do rio em consequência com a retirada das matas ciliares e consequentemente ao assoreamento que o rio vem sofrendo. POMPÊO et al., (2002) encontraram padrão semelhante em estudo realizado no Rio Pindaré, onde os valores representaram um aumento significativo nos meses de maio a novembro (153 a $410 \mu \mathrm{S} . \mathrm{cm}^{-1}$ ), respectivamente. Os valores referentes a esta variável se encontram superiores ao recomendado pela resolução CONAMA 357/05, para a classe 2 , que é de 1 a $100 \mu \mathrm{S} . \mathrm{cm}^{-1}$. 
Figura 2 - Variáveis físico-químicas das amostras de água da Bacia do Rio Pindaré nos trechos dos municípios de Pindaré - Mirim, Tufilândia e Alto Alegre no Estado do Maranhão
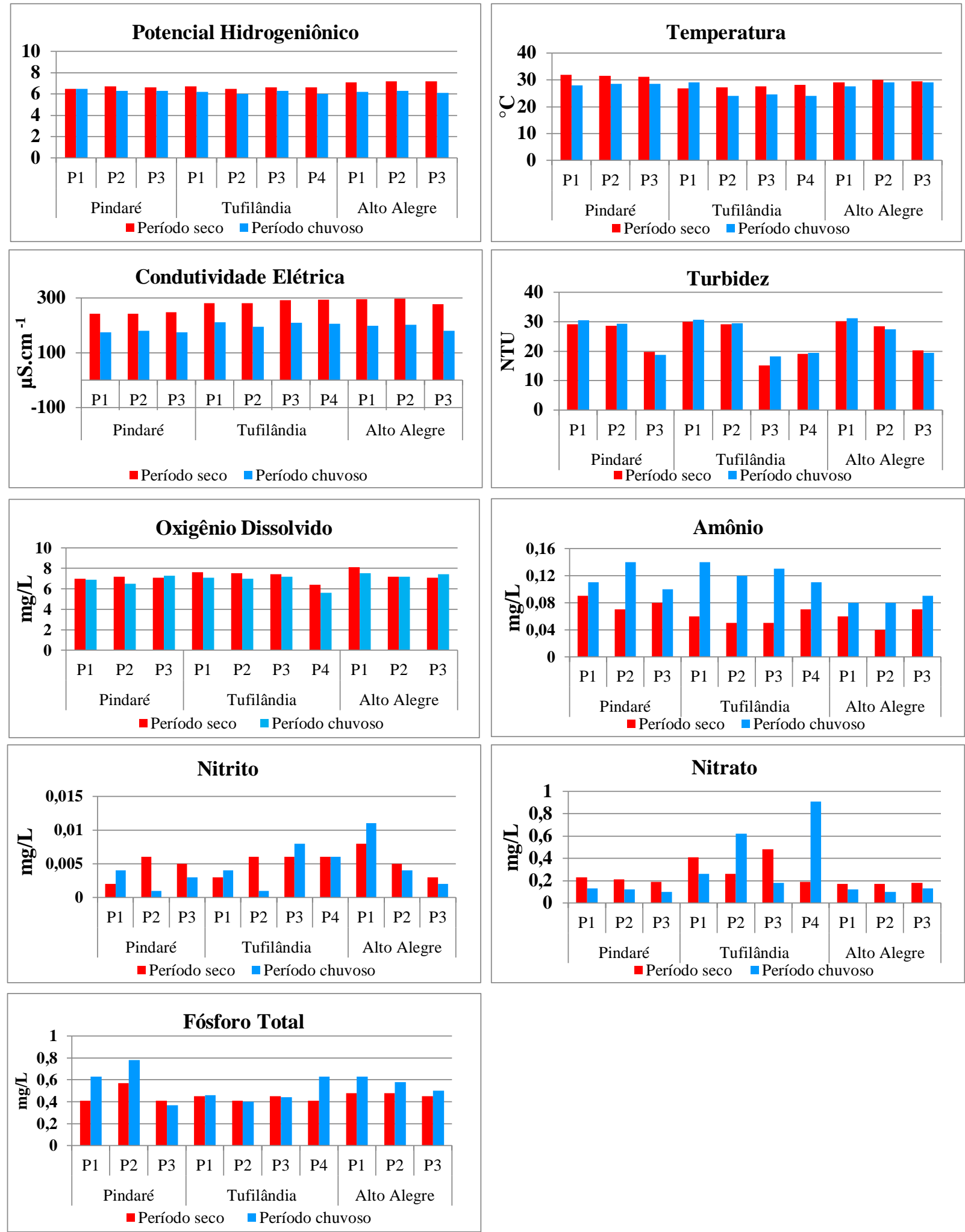

A turbidez não apresentou grande variação em seus valores, mas pode-se observar nitidamente que o período chuvoso apresentou os maiores valores, provavelmente ocasionado pela lixiviação do solo. As medidas desta variável estão em conformidade com o padrão estabelecido pela resolução CONAMA 357/05, que é de 100 UNT para a classe 2. Os valores obtidos neste estudo estão próximos aos registrados por Rodrigues (2011) em trabalho realizado na Bacia do Rio Pindaré.

O oxigênio dissolvido é um dos gases mais importantes na dinâmica e na caracterização de ecossistemas aquáticos. As concentrações mais elevadas podem ser explicadas provavelmente pela ocorrência das chuvas e a incidência dos ventos sobre a lâmina d'água. Variações semelhantes foram encontradas por Santos \& Carvalho, (2007) no Rio Munim, com concentrações mínimas de 5,8 mg.L-1, em estudos realizados nos rios do Maranhão. No Rio Tocantins, Borsatto et. al., (2010), encontrou valo- 
res médios de 7,6 mg. L1, na cidade de Imperatriz. Esses valores são considerados adequados para a manutenção da vida aquática, segundo os limites estabelecidos pela Resolução CONAMA $357 / 2005$ que é de 11,0 mg L-1, para a classe 2.

O fósforo total apresentou concentrações mais elevadas para o período chuvoso em todos os municípios, sendo bastante influenciado pela incidência de chuvas, período em que ocorre a lixiviação do solo da bacia. Segundo Tundisi (2008) a concentração desses compostos depende de processos geoquímicos. Os valores encontrados neste estudo foram superiores aos encontrados por Guimarães (2011) na Bacia do Rio Gurguéia no Estado do Piauí.

Em relação às formas de nitrogênio foi possivel observar que os valores podem está diretamente ligado à poluição orgânica e pode prejudicar a biota do ecossistema aquático. 0 mês de maio apresentou as maiores concentrações em relação aos nutrientes fósforo e amônio, podendo ser explicado devido à pluviosidade. Nessa época ocorrem lixiviamentos de materiais orgânicos e poluentes, porém as concentrações aumentam significativamente de um ponto para outro.

De acordo com Prado (2008) os vegetais reconhecem apenas as formas iônicas assimiláveis do nitrogênio (amônia e nitrato), e esses compostos em excesso no meio podem ocasionar florações de algais. Peixoto et al. (2014), monitorando a qualidade da água de acordo com a legislação CONAMA 375/05 para rios de classe 02, através dos parâmetros DBO, OD, Fósforo total, $\mathrm{pH}$ e óleos e graxas, concluíram que a água do Rio Been encontra-se com boa qualidade com todos os parâmetros avaliados dentro dos previstos pela legislação. A dominância do nitrato, no período chuvoso, parece refletir o processo de nitrificação favorecido pela aeração da coluna d'água. Os valores de nitrito e nitrato estão dentro dos limites da Resolução Conama 357/05, para a classe 2, (1,0 mg/L e 10,0 mg/L N, respectivamente).

O nitrito e nitrato apresentaram baixas concentrações no mês agosto, sendo que em maio de 2010 esses parâmetros não puderam ser analisados devido a problemas técnicos. Em Pindaré-
Mirim o nitrito apresentou uma variação entre $0,001 \mathrm{mgL}^{-1}$ (P2ago/11) e 0,009mgL-1 (P1 e P2-nov/10) no período seco, e entre 0,001 $\mathrm{mgL}^{-1}$ (P2 mai /11) e 0,04 mgL-1 (P1- mai /11) no chuvoso. Alto Alegre apresentou concentrações que ficaram entre 0, 003 $\mathrm{mgL}^{-1}$ (P3-ago/11) e 0,011 mgL-1 (P1-ago/11) no período seco, já o período chuvoso as concentrações ficaram entre 0,002 mgL-1 (P3- mai /11) e 0,011 mgL-1 (P1- mai /11). Para Tufilândia o nitrito variou de $0,001 \mathrm{mgL}^{-1}\left(\mathrm{P} 2\right.$-ago/11) a 0,007 $\mathrm{mgL}^{-1}(\mathrm{P} 2$, P4-nov/10 e P4-ago/11) no período seco e no período chuvoso a variação foi de $0,001 \mathrm{mgL}^{-1}$ (P2-ago/11) e 0,008 mgL-1 (P3mai /11).

Em contrapartida, o nitrato apresentou para Pindaré-Mirim concentrações que variaram entre 0,013 $\mathrm{mgL}^{-1}$ (P3-ago/11) e 0,337 $\mathrm{mgL}^{-1}$ (P1-nov/10) no período seco e 0,101 $\mathrm{mgL}^{-1}$ (P3 mai /11) e 0,130 mgL-1 (P1 mai /11) no período chuvoso. Para Alto Alegre foram registrados valores que variaram entre $0,102 \mathrm{mgL}-$ 1 (P2-ago/11) e 0,242 mgL-1 (P2-nov/10) no período seco e 0,102 $\mathrm{mgL}^{-1}\left(\mathrm{P} 2-\right.$ mai /11) e 0,138 $\mathrm{mgL}^{-1}(\mathrm{P} 3-\mathrm{mai} / 11)$ para o chuvoso. Em Tufilândia as concentrações de nitrato apresentaram valores que ficaram entre $0,259 \mathrm{mgL}^{-1}$ (P1-ago/11) e 0,700 $\mathrm{mgL}^{-1}$ (P4-ago/11) no período seco e no período chuvoso entre 0,186 mgL-1 (P3 mai /11) e 0,910 mgL-1 (P4- mai /11).

A análise de componentes principais é uma técnica de transformação de variáveis, onde cada uma pode ser considerada como um eixo de variabilidade estando usualmente correlacionada com outras variáveis. A partir da análise de Cluster foi possível observar claramente a ocorrência de dois agrupamentos, separados por período sazonal: I - pontos no período chuvoso e II pontos no período seco, onde as precipitações parecem interferir na dinâmica físico-química dos pontos dos municípios de Pindaré-Mirim, Tufilândia e Alto Alegre, (figura 3). A análise dos componentes principais, por sua vez, revelou as principais variáveis físicas e químicas da água que influenciaram nas características dos pontos amostrados, destacando as variáveis: condutividade elétrica e turbidez, (figura 4). ACP através da ordenação dos escores sugere que as características do Rio Pindaré são diferentes entre os períodos de cheia e seca nos três municípios testados. 
Figura 3 - Dendograma resultante da análise de agrupamento para as variáveis físicas e químicas da água da Bacia do Rio Pindaré nos trechos (Pindaré - Mirim (P), Tufilândia (T), e Alto Alegre (A)) em períodos sazonais seco (S) e chuvoso (C) de 2010 e 2011

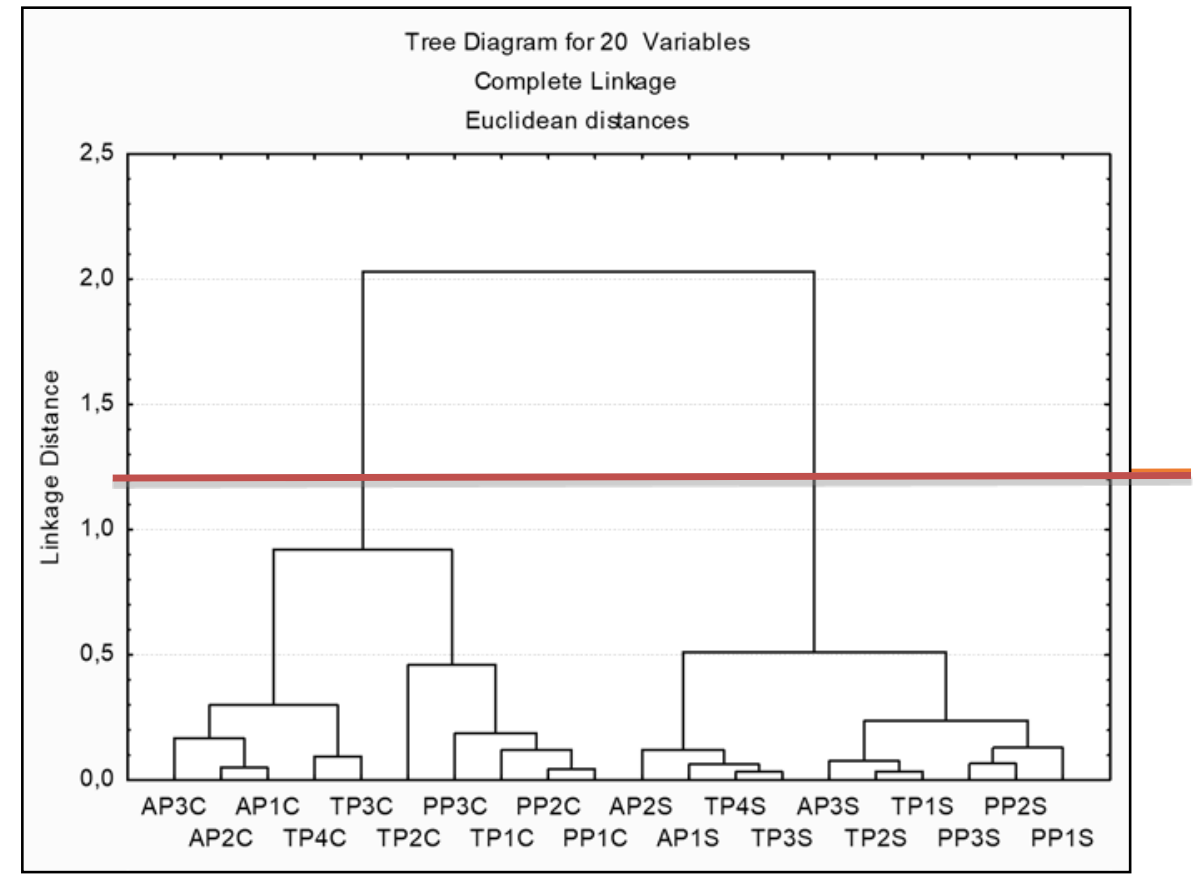

Figura 4 - Gráfico da Análise dos Componentes Principais, obtidas em amostras de água da Bacia do Rio Pindaré nos trechos (Pindaré- Mirim, Tufilândia, e Alto Alegre) em períodos sazonais de 2010 e 2011, no Estado do Maranhão

Corroborando com este trabalho, Bernardi et al. (2009), avaliando a influência das variáveis condicionantes: condutividade, $\mathrm{pH}$ e sólidos em suspensão através do AAPC, observou que as caraterísticas do Rio Madeira são diferentes em período seco e cheio, possivelmente influenciado pelo Rio Beni.

\section{CONCLUSÃO}

Este estudo confirma a complexidade natural dos ecossistemas estudados, bem como sua elevada fragilidade ambiental frente às ações antrópicas como exposto nos resultados onde mostraram grande influência. Sendo assim, as características físicas e químicas foram de extrema importância na dinâmica do ecossistema aquático no período sazonais sendo que os valores encontrados são considerados adequados para manutenção da vida aquática, segundo a resolução do CONAMA 357/2005.

\section{REFERÊNCIAS}

AMINOT, A. \& CHAUSSEPIED, M. Manuel desanalyseschimiques em milieux marin. CNEXO. Brest/France. 395p. 1983. 
ANDRADE, F. S.; SILVA, A. M.; ARIDE, P. H. R.; OLIVEIRA, A.T. Análise Físico-química e da Microbiota da Água do Lago Macurany, Parintins, Amazonas. Biota Amazônia Open Journal System, n. 6, p. 132-134, 2016.

APHA. Standard Methods for the examination of water and wastewaters. 25 ed. New York, McGraw-HILL, 1995. 720p.

ATLAS DO MARANHÃO. Gerência de Planejamento e Desenvolvimento econômico, Laboratório de Geoprocessamento - UEMA. São Luís: GEPLAN 2002.42p.

BACIAS DO NORDESTE. Relatório estatístico hidroviário 1998, 1999 e 2000. Disponível em: http://www.transportes.gov.br/modal/hidroviário/ESTATÍSTICA/Baciapinda ré.htm. Acesso em: 20/05/2014.

BERNARDI, J. V. E.; LACERDA, L. D.; DÓREA, J. G.; LANDIM, P. M. B.; GO MES, J. P. O.; ALMEIDA, R., MANZATTO, A. G.; BASTOS, W. R. Aplicação da Análise de Componentes Principais na Ordenação dos Parâmetros Físico-químicos no Alto Rio Madeira e Afluentes, Amazônia Ocidental. Geochimica Braziliensis, n. 23, p. 79-90, 2009.

BETEMPS, G. R.; SANCHES FILHO, P. J.; KERSTNER, T. Caracterização físico química da água e determinação de metais pesados $(\mathrm{Cr}, \mathrm{Cu}, \mathrm{Pb}$ e Zn) no sedimento do riacho Arroio do Padre (Arroio do Padre, Brasil/RS). Revista Thema, v. 1, n. 2, p. 5-19, 2014.

BORSATTO, J. C. L.; BORSATTO, M. V.; ORLANDO, J. F. F.; SILVA, M. F.; SILVA, D. G. K. C. Análise da qualidade da água nos rios Tocantins e cacau no trecho da construção da ponte da amizade Engenharia Ambiental - Espírito Santo do Pinhal, v. 7, n. 2, abr. /jun. p. 163-177, 2010.

BRAGA, B.; HESPANHOL, I.; CONEJO, J.G.L.; BARROS, M.T.L.; VERAS JÚNIOR, M.S.; PORTO, M.F.A.; NUCCI, N.L.R.; JULIANO, N.M.A.; EIGER, S. Introdução à engenharia ambiental. 2 ed. São Paulo: Prentice Hall, 2003.

BRANCO, S. M. Água: origem, uso e preservação. São Paulo: Moderna, 1993.

GAUDETTE, H. E.; FLIGHT, W. R.; TONER, L.; OOLGER, D.W. Na inexpensive titration method for the determination of organic carbon in recent sediments. Journal of Sedimentary Petrology, n. 44, p. 249 - 253, 1974.

GOLTERMAN, H. L., CLYMO, R.S.; OHSNTAD, M. A. M. Methods for physical and chemical analysis of freshwaters.2 ed. IBP Handbook, 8. BlackwellSci.Publ, Oxford, 1978.

GUIMARÃES, G. S. C. Estimativas de cargas de fósforo total e de material particulado em suspensão (MPS) da bacia superior do rio Gurguéia. Monografia, Universidade Federal do Piauí-UFPI, 2011.

HOLANDA, F. S. R.; SANTOS, L. G. C.; SANTOS, C. M. S.; CASADO, A. P. B.; PEDROTTI. Controle da erosão em margens de cursos d'água: das soluções empíricas à técnica da bioengenharia de solos, River bank erosion control at streams margin: from empiricism to soil bioengineering technique. R. RA`EGA, Curitiba: Editora UFPR, n. 17, 2009.

HONGYU, K. Comparação do GGEbiplot ponderado e AMMI-ponderado com outros modelos de interação genótipo $\times$ ambiente. Tese (Doutorado em Estatística e Experimentação Agronômica) - Escola Superior de Agricultura "Luiz de Queiroz", Universidade de São Paulo, Piracicaba, 2015. 155p.

IBGE Histórico de cidades, Disponível em: http://www.ibge.gov.br/cidadesat/topwindow.htm?1. Acesso em: 23 jun. 2014
JOHNSON, R.A.; WICHERN, D.W. Applied multivariate statistical analysis. Madison: Prentice Hall International, 1998. 816p.

LITE, A. C. Aspectos agroindustriais do Estado do Maranhão. São Luís: Secretaria da Agricultura do Estado do Maranhão, Departamento de Pesquisa e Experimentação. 1976.

MARANHÃO. Gerência de Planejamento e Desenvolvimento Econômico. Laboratório de Geoprocessamento. Atlas do Maranhão. São Luís, 2006.

MONTEIRO, D. S. Variação especial e sazonal do fitoplâncton no estuário do rio Preguiças no município de Barreirinhas, Maranhão-Brasil. Monografia Ciências Aquáticas-UFMA, 2008.

PEIXOTO, R. H. P. B. Sobre a qualidade da água do Rio Tocantins a jusante da Usina Hidrelétrica Serra da Mesa (GO). Dissertação de Mestrado. Campina Grande-PB, 2001.

PEIXOTO, K. L. G.; NOUGUCH, H. S; PEREIRA, A. R.; MARCHETTO, M.; SANTOS, A. A. Avaliação das Características Quali-Quantitativa das Águas do Rio Beem, Município de Humaitá-Amazonas. Avaliação das Características Quali-Quantitativa das Águas do Rio Beem, Município de Humaitá-Amazonas. Engineering and Science, v. 2, p. 113, 2014.

PEREIRA, A. A.; HUNGRIA, M.; FRANCHINI, J. C.; KASCHUK, G.; CHUEIRI, L. M. DE O.; CAMPO, R. J.; TORRES, E. Variações qualitativas e quantitativas na microbiota do solo e na fixação biológica do nitrogênio sob diferentes manejos com soja. Revista Brasileira de Ciência do Solo, n. 31 , p. 1397-1412, 2007.

POMPÊO, M. L. M.; MOSCHINI-CARLOS, V.; SILVA-FILHO, C. G. Transporte de nitrogênio, fósforo e seston em três rios pré-amazônicos, 2002.

PRADO, R. M. Nutrição de plantas. São Paulo: Editora UNESP, 2008.

RODRIGUES, E.H.C. Ecologia do fitoplâncton de um trecho do médio Pindaré. Monografia, São Luís, UFMA, Maranhão- Brasil. 2011.

RODRIGUES, E.H.C; SILVA, M.R.C; ET AL. Variação temporal do fitoplâncton em um rio tropical pré-amazônico (Rio Pindaré, Maranhão, Brasil). Ciência e Natura, v. 37, n. 2, p. 241 - 251, 2015.

SANTANA, S. H. C ET. AL. Estudo de parâmetros de qualidade de água e análise de imagens do Landsat5 referente ao oeste da região do Submédio São Francisco. In: SIMPÓSIO BRASILEIRO DE SENSORIAMENTO REMOTO, 15., 2011. Anais... Curitiba, 2011.

SANTOS, E. A.; CARVALHO, R. N. Monitoramento da Bacia Hidrográfica do Rio Munim-Ma. In: Semana Estadual de Recursos Hídricos, 2., 2007. Anais... São Luís, 2007.

SEMATUR. 1991. Diagnóstico dos Principais Problemas Ambientais do Estado do Maranhão. Secretaria do Estado do Meio Ambiente e Turismo, São Luís, p.19.

SCHENEIDER, R. M. et. al. Estudo da influência do uso e ocupação de solo na qualidade da água de dois córregos da Bacia hidrográfica do rio Pirapó. Acta Scientiarum Technology, v. 33, n. 3, 295-303, p. 2011.

STRICKLAND, J. D. H.; PARSONS, T. R. A pratical handbook of seawater analysis. Bulletin Fisheries Board of Canadá Otawa, n. 167, p. 1-311, 1968.

TUNDISI, J. G. Limnologia, São Paulo, Oficina de textos, 2008. 